\title{
La teología progresista europea ante la teología de la liberación
}

\section{Juan-José Tamayo-Acosta, Madrid.}

La teología latinoamericana de la liberación constituye un fenómeno sin precedentes en la reciente historia del pensamiento cristiano. Por primera vez una creación teológica del tercer mundo ha adquirido relevancia y significación en Europa, donde ha producido un impacto insospechado y ha concitado las más encontradas reacciones. Por una parte, ha penetrado en las viejas aulas de seminarios y facultades de teologia y ha dejado su impronta en los mís prestigiosos y creativos teólogos europeos. Por otra, ha recibido duras condenas (si bien últimamente matizadas) de los más altos organismos vaticanos y de los téologos oficiales.

Se trata, como es bien sabido, de un discurso teológico no estructurado miméticamente a partir del europeo, sino elaborado desde la propia realidad latinoamericana, con unas seflas de identidad propias, con una metodologia original, y que quiere responder, desde la fe, a los desaffos políticos, socioeconómicos, culturales y religiosos del continente y, más en concreto, a la sibuación de dependencia en que vive América Latina multisecularmente.

El testimonio de dos teólogos latinoamericanos de comienzos de los aflos sesenta confirma lo dicho.

Afirmaba el té́logo uruguryo Juan-Luis Segundo: "La toologia latinoamericana no lo será por 'aplicar' a América Latina a la teologfa hecha en Europa, a la manera que una sucursal se limita a tratar una cierta temática más concreta que la casa central... Nuestro intento aqui es reflexionar en la condición de alienación propia de la teología en el continente latinoamericano. Porque es evidente que una realidad humana con caracteristicas propias no debe carecer de teología, es decir, de una traducción del mensaje cristiano a la propia realidad."1

Hugo Assman escribla: "Si la sibuación de dependencia y dominación de dos tercios de la humanidad con sus treinta millones anuales de muertos de hambre y desnutrición, no se convierte en el punto de partida de cualquier teologia cristiana hoy, aun en los paises ricos y dominadores, la teologia no podrá situar y con- 
cretizar históricamente sus temas fundamentales. Sus preguntas no serán preguntas reales... Por eso... es necesario salvar a la teologia de su cinismo. Porque realmente frente a los problemas del mundo de hoy, muchos escritos teologicos se reducen a cinismo. ${ }^{2}$

La teologia de la liberación (TL) tuvo conciencia, desde el inicio, de su carácter particular o regional, según el contexto en que se gestaba, pero, al mismo tiempo, en ningún momento ha renunciado a su voluntad de universalidad.

A su vez, esta teologia, que pretende ser tal y no puro testimonialismo y que tiene unos presupuestos noéticos bien definidos, posee sus peculiaridades. En primer lugar, no se elabora en lo recóndito de las bibliotecas monacales de antaflo, ni en los emporios académicos del saber, ni en los clásicos lugares donde se concentran el saber teológico y el poder eclesiástico.

En segundo lugar, se gesta en el marco de los procesos y movimientos históricos de liberación que existen en América Latina - de ahí su dimensión socio-politica que le es consustancial-, en los espacios del no saber y del no tener - de ahr su caracter profético y de denuncia-, en la periferia del mundo -de ahí que sea acusada con frecuencia de marginal y parcial. Ello no significa renunciar a lo que ha definido tradicionalmente a la teologfa, es decir, a dar razon de la fe y de la esperanza. La pretensión de la TL es dar razón de la fe en el Dios de los pobres o, en la expresión feliz de Ignacio Ellacuria, "dar razones de la razón del pueblo creyente."

Hasta no hace mucho tiempo, y todavla hoy entre no pocos teologos de escuela, la única teologia reconocida como tal era la acadénica, la elaborada por teólogos de profesión en facultades de teologí, al servicio de la institución eclesiástica y del magisterio. Hoy, como observa atinadamente Metz, junto a esta forma de hacer teología aparece otra no menos importante, que no puede caracterizarse simplemente como teologia de base, uno de cuyos ejemplos es la TL, además de la teología negra y la teología feminista; 3 una teologla que quiere armonizar y combinar adecuadamente esfuerzo metodológico y voluntad profética.

Mi propósito en esta intervención no es hacer una presentación de la TL, de sobra conocida por quienes van a tener acceso a este texto, sino analizar les relaciones entre ella y la teologfa elaborada en Europa, centrando la atención de manera preferente en la llamada "progresista": ver si existen relaciones entre ambas y de qué tipo; si se da diálogo y escucha, si hay intercomuniceción y apertura, si hay confrontación y debate sin escamotear las cuestiones de fondo; 0 si, por el contrario, priman el recelo y la desconfianza, la indiferencia o el rechazo global. Y ello teniendo en cuenta los testimonios de algunos de los representantes más significativos de ambas teologias.

La exposición se estructura en tres partes: la primera, más breve y sencilla, intentará aproximarse a los diferentes contextos en que ambas se enmarcan; la segunda estudiara el posicionamiento de la TL ante la teologia progresista europea; la tercera analizará la acogida prestada por ésta a la TL. 


\section{Un marco hlst6rico, social y religloso diferente}

Empecemos por recordar algo que parece obvio, pero que con demasiada frecuencia suele olvidarse: Europa no es América Latina ni cultural, ni política, ni social, ni religiosamente. Clodovis Boff, tras una prolongada estancia en Europa que le permitió conocer más de cerca el cristianismo europeo, establecía tres diferencias fundamentales entre las iglesias europea y latinoamericana y sus respectivos contextos. 4

\section{Diferencla histórica}

El cristianismo, recuerda, esté implantado en Europa desde hace casi dos milenios; tiene, por ende, una larga y dilatada historia tras de sf. El cristianismo latinoamericano es más joven, apenas tiene quinientos afios (estamos a punto de celebrar el quinto centenario del "descubrimiento" y, en consecuencia, del nacimiento de la fe cristiana en ese continente).

Pues bien, esa diferencia histórica no deja de ser ambivalente: por una parte, la Iglesia europea puede apelar a una tradición más arraigada en el tiempo; por otra, la tradición suele jugar, a veces, en contra de la genuinidad del mensaje y a favor de su desnaturalización. Merece la pena citar a este respecto el testimonio de Sandhu Singh:

Un día me encontraba yo sentado

a orillas de un rio. Metí

la mano en el ague, cogf un

guijarro redondeado y lo part.

Por dentro estaba seco. Esa

piedra habia permanecido mucho tiempo dentro del rí,

y sin embargo

el agua no hable penetrado en

ella. Entonces pense que lo

mismo les ocurifa a los hombres

de Europa Durante centuriag

han estado sumergidos en el

cristianiseno, pero éste no ha

penetrado en ellos. 5

De lo que no cabe duda es que resulta más fácil, como observa C. Boff, "construir una comunidad eclesial en un terreno nuevo" que "en un terreno ya estructuredo." Las posibilidades de novedad, de creatividad y de apertura son mayores en el primer caso que en el segundo. Ello explica, en cierta medida, por que la Iglesia latinoamericana ha conseguido dar pasos de gigante en estos últimos veinte afios de posconcilio, mientras que las iglesias europeas han ido mÁs despacio e incluso han dado mancha arras en muchos campos. 


\section{Diferencia social}

La Iglesia europea vive en medio de una sociedad desarrollada, de capitalismo avanzado, con una estructura democráfico-liberal de carácter estable; y no es previsible que en su seno se produzcan convulsiones significativas. La Iglesia latinoamericana, por el contrario, está inmersa en una sociedad subdesarrollada, en una sociedad de capitalismo todavia salvaje, con una estructura política dictatorial en varios paises del continente y con la amenaza permanente en otros.

$Y$ todo hace pensar que la Iglesia europea se encuentra perfectamente instalada en esa sociedad, legitima el sistema y, como premio, se ve legitimada por el sistema Se observa cierta connivencia con el statu quo. Al no ser tan fuertes las contradicciones, resulta dificil que resurja el viejo esplritu de profecla, salvo en grupos marginales, que no son tenidos en cuenta por la institución eclesiástica.

La Iglesia latinoamericana vive en medio de un volcán que amenaza con hacer erupción en cada momento. Por ello "la fe se encuentra más fuertemente compelida a la profecla y al martirio" (C. Boff).

Lo más que puede esperarse de las iglesias europeas son llamadas a la prudencia, al equilibrio, a la moderación; y diffcilmente invitaciones al radicalismo evangélico, a hacer realidad los valores del reino, a vivir el espíritu de las bienaventuranzas, Pues dichas invitaciones convertirlan, ipso facto, a la institución eclesial en fuerza marginal y comunidad de contraste. $Y$ no parece que las iglesias europeas en su conjunto estén dispuestas a pagar tan caro precio. A la Iglesia europea se le podrfa aplicar lo que de la Iglesia en general afirmaba la revista Iglesia viva:

Ha cedido con frecuencia a la tentación del "termino medio." Ha recortado los extremismos evangélicos para hacer posible que el camello pase por el ojo de la aguja $\mathrm{Ha}$ inventado, segín una expresión feliz, el camello enano. ${ }^{6}$

La Iglesia europea siente un miedo cerval, enfermizo diria yo, hacia el marxismo, hacia las revoluciones sociales, hacia los cambios profundos. $Y$ uno no puede menos que preguntarse si ese miedo no sera, más bien, una coraza para defenderse del evangelio, si detrás del ese miedo no se esconde, en realidad, un verdadero pavor a los pobres, que pueden echarle en cara su silencio cómplice 0 sus alianzas con los causantes de los pobres y de la pobreza.

Con todo, a pesar de las diferencias, sigue existiendo una base común a Europa y a America Latina: el sistema capitalista, la sociedad de clases, que, en ambas latitudes constituye, eunque con matices importantes, el dogma más afirmado y el fetiche o idolo más reverenciado. En ambas se da una estructura social piramidal, aunque la pirámide latinoamericana es más puntiaguda.

\section{Diferencia rellgiosa}

Mientras en Europa viene produciéndose desde hace varios siglos un proceso de secularización en todos los ámbitos de la vida (social, cultural, político, eco- 
nómico, etc.), a través del cual la sociedad se siente liberada de toda tutela religiosa, en América Latina la sociedad sigue siendo mayoritariamente cristiana y estructuralmente religiosa.

Mientras en Europa la secularización ha estado marcada por actitudes rabiosamente anticlericales, en América Latina el cambio religioso no ha revestido formas irreligiosas o anticlericales.

Mientras en Europa se ha dado un fenómeno generalizado de desafección del pueblo, y más en concreto de la clase trabajadora, hacia las instituciones eclesí́sticas, en América Latina el pueblo sencillo continúa siendo extremadamente sensible a la llamada religiosa y sigue abierto a la presencia de la Iglesia.

Mientras en Europa los movimientos cristianos proféticos de después del Concilio Vaticano II surgieron en conflicto con la estructura jerárquica eclesiástica, en América Latina las comunidades de base y otros movimientos eclesiales han contado con el apoyo y la animación incondicionales de un importante sector de obispos. Si en el primer caso la Iglesia institucional ha marginado a esos movimientos, en el segundo ha sido la propia institución, en muchos casos, la que ha hecho de ellos cauces prioritarios de evangelización.

Mientras en Europa el cristianismo progresista se ha despreocupado, con frecuencia, de la religiosidad popular por considerarla alienante y la anatematizado en bloque sin un análisis previo, en América Latina la religiosidad del pueblo sencillo ha sido y sigue siendo hoy un instrumento válido de evangelización, con no pocos elementos liberadores.

\section{La teologí de la liberación ante la teología progresista europes}

Suele acusarse con relativa frecuencia a los teólogos latinoamericanos de la liberación de sentir desprecio o rechazo, o al menos desinteres, hacia la teología europea de corte progresista El téblogo francés Claude Geffré afirmaba lo siguiente en la presentación del número 96 de la revista Concilium, dedicado todo entero a la TL y en el que colaboraba buena parte de los creadores de la TL: "Pero lo que a nuestro parecer resulta más sorprendente es que los teólogos latinoamericanos rechazan de manera aún más radical (que el neointegrismo que se desarrolla actualmente en los Estados Unidos y en algunos paises de Europa) las distintas teologias 'progresistas' del mundo occidental, ya se trate de las 'teologias de la secularización' o de la 'política'."7

Un aflo después, en el congreso de teología latinoamericana celebrado en México, Jon Sobrino retomaba esa apreciación de Geffré y matizaba el sentido preciso de ese desinteres, que, a su juicio, no debfa entenderse como desconocimiento de la teología europea, ni como desprecio o sentimiento de superioridad, ni como desdén hacia los logros innegables de esa teologla Se trata más bien, de 
la falta de sintonia de interes del conocimiento teologico. Sobrino observaba entonces, y con razón, que mientras la teologia europea se comprenda a sí misma desde el centro geopolítico del mundo, le serf imposible captar la miseria y hara el juego, aun inconscientemente, a lo sociedad capitalista occidental.

Con todo, hay que constatar que buena parte de los tedogos latinoamericanos de la liberación se han formado en universidades europeas y en ellas han adquirido un bagaje intelectual que les ha servido para mejor articular su reflexión teológica. Ellos mismos utilizan instrumentos propios de la tradición y de la teologfa europea, y mury especialmente de la llamada teologia progresista Reconocen de forma explícita la riqueza conceptual y los importantes logros de esa teologia, fijándose, entre otros, en los siguientes: los avances en la investigación exegetica; la liberación del dogmatismo y de la ortodoxia abstracta; la preocupación por dar sentido a una fe que parecfa carecer de el; el redescubrimiento de las mediaciones sociopolíticas de la fe, con el consiguiente esfuerzo por superar actitudes privatizadoras del cristianismo; la recuperación de la memoria peligrosa y la subversiva de la tradición judeo-cristiana, que pone en marcha un proceso de transformación social, etc.

Los téologos de la liberación no rechazan globalmente las teologias elaboradas en el centro, si bien toman sus distancias, adoptan una actitud crítica y, con la intención de reafimar su identidad y peculiaridad, destacan el momento de ruptura con ellas. De una parte, ruptura política, como subraya G. Gutiérrez, definida por la conflictividad polf́tica entre sus respectivos interlocutores; de otra, ruptura epistemológica con los viejos modos de conocer, que no son capaces de dar cuenta de los problemas propios del tercer mundo.

El momento de ruptura deriva, cree Girardi,de la centralidad que la TL reconoce, en su análisis de la realidad, a la conflictividad social y de la centralidad que concede a la praxis de liberación.

Un primer momento de rupara y de diferencia se refiere a los intereses y al modo de acercarse a la realidad en una y otra teologia. Es algo que ha puesto de relieve con agudeza y precisión Jon Sobrino, ${ }^{8}$ para quien la teología europea se acerca a la realidad en cuanto pensada, es decir, preferentemente desde las mediaciones del pensamiento (culurra, filosofia, teologia) y tiende a reconciliar la miseria dentro del pensamiento teológico, y no a liberar a la realidad de su miserig.

La teologfa europea enlaza con la primera ilustración, y su interes se centra en liberar a la razón del autoritarismo y del dogmatismo, en liberar a la subjetividad esclavizada.

La TL intenta responder, más bien, al reto de la llamada segunda ilustración. Para ella, la función liberadora del conocimiento se concreta en la transformación de la realidad, recuperando, asi, el sentido amenazado de la fe. Para la TL, el conocimiento no posee un carácter puramente interpretativo, "no es nunca ni 
práxica ni valorativamente neutral, tiene siempre implícita o explicitamente un carácter práxico y ético."

Un segundo punto de diferencia-ruptura se refiere a los interlocutores, sujetos sociales, desaffos y preguntas a los que una y otra teologia intentan responder. En este aspecto ha profundizado Gustavo Gutierrez, ${ }^{9}$ quien constata que el interlocutor privilegiado de la teologia europea progresista es el burgués no creyente, ateo o escéptico, el espiritu moderno y la ideologia liberal, cuyo sujeto es la clase burguesa. Según esto, el desafio le viene a esa teología de la crítica de la religión, de la secularización, del atef́smo. La tensión se da entre teísmo-ateísmo. y ello de forma más acusada en la teología europea oficial. Un buen ejemplo de ello puede verse en la contraposición que determinados teólogos espaftoles establecen entre la cultura laica y la cultura de la fe.

Las preguntas a las que intenta responder la teología europea son las mismas que ya se planteara el Bonhoeffer de las cartas de la prisión: $\iota c o ́ m o$ hablar de Dios en un mundo adulto y mayor de edad que se ha emancipado de la religión? ¿cómo hacer crelble a Dios en medio de la increencia?

Pues bien, la teologia elaborada como respuesta a esas preguntas, por lo demás insoslayables y muy importantes en Europa, no tiene en cuenta con frecuencia, cree Gutiérrez, "que las personas son los nuevos sujetos dominantes en la humanidad y que ellas han dado, como subproducto, las no personas, los pobres de hoy." 10 Es más, "pensar dentro de la mentalidad modema, sin asumir teologicamente que ella ha acompantado, y justificado, un proceso creador de un mundo nuevo de despojo e injusticia, no da más." Porque si bien es cierto que el origen de la opresión humana no se encuentra en la modernidad, también es cierto que el hombre moderno que interroga a la fe y al que intenta responder la teología europea "es el mismo que pertenece a grupos sociales, a culturas, a paises que crean nuevas formas de dominación." 11

Los interlocutores privilegiados de la TL son, por el contarrio, las mayorias oprimidas de América Latina, "los ausentes y anónimos de la historia, los "Cristos azotados": clases explotadas, culturas despreciadas, razes marginadas. Y las preguntas a las que quiere dar respuesta son de otro orden que las de la teologia moderna: ¿Cómo anunciar a Dios como padre de todos y generador de hermandad, en un mundo no humano, injusto e insolidario? ¿Cómo hablar de Dios a las victimas de la historia moderna de la libertad? ¿Cómo hablar de Dios desce la oura cara, desde "el reverso de la historia"? ¿Cómo anunciar el evangelio que es proclama de vida en una situción que lleva el sello de la muerte? ¿Cómo ser cristianos en un mundo pobre y empobrecido, sin rebelarse contra la miseria que clama al cielo? $\mathrm{Y}$, asi, otras muchas interrogantes que podriamos lanzar.

En consecuencia, el desafio de la TL no es el atelsmo, sino la idolatria, ese conjunto de idolos que siembran la muerte por doquier y exigen sacrificios de vidas humana en aras del mantenimiento de un orden que favorece sólo a unos pocos. 
Una tercera diferencia radica en el modo de entender las relaciones entre esperanza cristiana y realidad histórica. Sobre ella ha llamado la atención de manera especial Juan-Luis Segundo,12 quien observa cómo la teologia europea, partiendo de la reserva escatológica, relativiza utopfas intrahistoricas por igual, como si todas ellas fueran equidistantes del reino de Dios. Mientras que la TL entiende que no todos los proyectos históricos se encuentran a la misma distancia del reino de Dios. Por ello establece una jerarquización de los mismos: en la medida en que determinados proyectos consigan mayores cotas de justicia, fraternidad, igualdad, libertad y reconcialización entre los hombres y los pueblos, esos proyectos se encuentran más cerca del reino de Dios que los que actían en contra de los valores mencionados. Es más, Juan Luis Segundo establece una relación de causalidad, si bien efimera y frágil, entre los proyectos históricos de liberación y el reino de Dios.

La TL echa en falta, en cuarto lugar, en las teologías europeas la importancia de ln praxis liberadora en la construcción del reino. Laguna que hay que corregir, a juicio de Sobrino, insistiendo en que el reino de Dios exige una prática que lleva a realizaciones parciales de ese reino a través de mediaciones históricas concretas. Porque, aun cuando el reino de Dios, en cuanto utópico, no llega a ser adecuadamente realizable, lo cierto es que "principia realidades, prácticas, actitudes y valores historicos." 13 Por eso, ser fieles al reino comporta "realizarlo, ser atraído siempre de nuevo por esa plenitud y ser movido siempre de nuevo a su realización. Esa realización del reino de Dios es la finalidad última de la $T L$, que por ello ha sido comprendido como el momento ideológico de una praxis eclesial e histórica (Ellacuria)."14

Hay, en quinto lugar, una crfica del cautiverio intrasistémico en que se encuentra la teología europea, teologia constituida en un sistema de conceptos y elaborada mediante interpretaciones de interpretaciones, como observa Boff. 15 Crítica que se extiende a su alo grado de abstracción, lo que le hace sentir miedo a nombrar directamente los mecanismos de dominación. Crítica también, y por igual, al imperio y a la omnipotencia de la razón ilustrada como instancia última, lo que comporta, a su vez, una gran fragilidad, como en el caso del dinosaurio, que recuerdan Boff y Alves, el animal más grande y poderoso de la tierra, que desapareció por ser excesivamente fuerte y, a la postre, demasiado frágil para resistir las transformaciones de la vida.

La crítica se centra de manera especial en la teología de la esperanza de Molmann y en la teología política de Metz.

Al primero se le critica su dificultad para proponer, más allá del proyecto vigente del sistema y más acá del proyecto escatológico, un proyecto histórico de liberación polf́tica, económica, culural y sexual. ${ }^{16}$ A juicio de Dussel, la teologia de la esperanza de Moltmann opera solamente como reactivante ético profesional, y no como movimiento subversivo de la totalidad del sistema. 
Especialmente crítico con la teología de la esperanza de Moltmann se ha mostrado el teblogo brasilefio Rubén Alves, ${ }^{17}$ según el cual el futuro al que se refiere Molımann ya está predeterminado, es un objeto y no un horizonte; el futuro que se anticipa ya como presente no tiene capacidad para negar el presente, para cuestionarlo en sus elementos constitutivos. En la teologfa de la esperanza ve Alves una tendencia hacia el docetismo, pues no es la encamación la madre del futuro, sino que es el futuro trascendental el que hace al hombre sabedor de la encarnación.

A Metz la TL le hace ver que su critica profética se enmarca dentro del ámbito nacional, pasándole inadvertida la injusticia internacional provocada por el primer mundo, y su crítica desprivatizadora sólo afecta a elementos intemos del sistema, no al sistema en cuanto tal ni a sus raíces.

Pero, aun reconociendo la existencia de las diferencias y de un momento de ruptura entre la TL y la teología europea progresista, la cuestión fundamental no pasa necesariamente por la contraposición entre una y otra teologia. El límite entre opresión y liberación, como apunta Pablo Richard, no pasa entre continentes, sino entre opresores y oprimidos, y se encuentra también en el interior de cada uno de nosotros. Conviene recordar a este respecto que también en América Latina se elabora una teologra ligada a los centros de poder y dependiente de Europa, y que en Europa se elabora una teología sensible y ligada al tercer mundo y a las periferias.

La rafz de la contradicción principal en la actual confrontación teológica hay que buscarla en la dialéctica opresión-liberación. Ello explica que los teologos de la liberación luchen denodadamente por huir tanto de cierto chauvinismo como de ciento complejo de culpa general europea.

Concluyendo, podemos decir que la actitud critica y el hecho de acentuar el momento de ruptura no significan cerrarse al diálogo con la teología europea progresista. Antes al contrario, cada vez son mayores y más amplias las plataformas de comunicación. En los diferentes encuentros de la Asociación Ecuménica de Téblogos del Tercer Mundo, la mano sigue tendida y las llamadas al diálogo entre la teología de la periferia y la del centro son constantes, aunque con importantes salvedades, como pone de manifesto Dussel: "En los diálogos de la periferia se han manifestado las diferencias entre Africa, Asia y América Latina y también las del centro con la periferia. También se han descubierto los puentes de posibles soluciones para comprender la posición del otro y, así, alcanzar métodos y categorias (paradigmas) capaces de abrirse a una futura teología mundial, nueva cotalidad analógica que se construirá en el siglo XXI desde los particularismos afirmados y desarrollados (entre ellos, como particulares, Europa y EE.UU.)."18

Para que el dílogo sea posible y fructifero es preciso, de una parte, que las teologias norallánticas dejen de operar como formas de dominación cultural para con el tercer mundo; y, de otra, que unas y otras teologias se reconozcan como respuestas particulares a situaciones particulares, pues es desde los particula- 
risnos como puede consiruirse esa futura teologla universal por la que aboga Dussel.

\section{La teologia europea ante la TL}

La TL ha tenido un amplio eco en toda Europa, aunque con reacciones muy dispares y encontradas: ha sido objeto de estudio en números monograficos de précticamente todas las revistas de pensamiento cristiano, en simposios, congresos, cursos de teologia, encuentros de pastoral. Ha servido de fuente de inspiración para la rellexión teológica, la vida y la praxis emancipadora de las comunidades de base y de los movimientos cristianos proféticos surgidos en la Iglesia desputs del Vaticano II.

Buena parte de los cultivadores de la TL han sido honrados por diferentes universidades catolicas y facultades de leologia europeas con el titulo de doctores honoris causa; lo que, más allá del tutulo en sf, significa un reconocimiento académico a su quehacer teológico.

Teólogos nada sospechosos de jugar a tercermundistas, como Rahner, Schillebeeck, Chenu, Duquoc, Alfaro, Metz, Molmann, han ejercido el no siempre bien visto papel de defensores de esa teología.

Pero las reacciones de los teólogos europeos están muy lejos de ser unánimes y van desde la sospecha, la amenaza y la condena hasta el apoyo más entusiasta.

Vamos a pasar revista a algunas de esas reacciones, ordenándolas por razones de afinidad.

\section{Indiferencia y condena}

Cuando la TL comenzó a difundirse en Europa en los inicios de la década de los setenta, no pocos sectores teológicos europeos, los vinculados sobre todo a la toologia oficial y académica, adoptaron una actitud de desinterés e indiferencia, mezclada con un no disimulado complejo de superioridad, por enteder que la TL no podla aportar nada nuevo al debate teológico. Lo mismo que los coetáneos de Jesús se preguntaban con escepticismo si de Nazaret podía salir algo bueno, dichos sectores se preguntaban si de Amérca Latina, continente subdesarrollado cultural y teologicamente, podian surgir aportaciones importantes para la teologia europea, para responder negativamente, habida cuenta de que Europa era la cuna del pensamiento, de las revoluciones científicas, del buen hacer teologia, de los métodos histórico-críticos y de otras conquistas. Con una arrogancia desmedida consideraban a la TL una corriente de moda a la que no habla que prestar demasiada atención por tratarse de un producto pasajero y poco consistente.

Quienes asi reaccionaban entonces venían a demostrar lo arraigado que se encontraba el eurocentrismo teologico y eclesial. Con su actitud denotaban una gran insensibilidad hacia la problemática norte/sur, países pobres/palses ricos, 
pueblos desarrollados/pueblos subdesarrollados, iglesias del primer mundo/iglesias del tercer mundo. Denotaban, asimismo, una injustificable insolidaridad con los más desfavorecidos y un desdén ante la invitación que habla hecho el Concilio Varicano II a hacer la reflexión teológica a partir de las seffas de identidad de cada pueblo. Su estrechez teológica quedaba bien a las claras, pues para esos sectores -y ése era el problema de fondo- la problemática planteada por la TL resultaba ajena de todo punto a la teología.

Uns variante de esta postura que estamos comentando la constituyen quienes no reconocen a la TL el estatuto teológico y la reducen a mera teoría sociológica de la sociedad latinoamericana o consideran a sus cultivadores como teologos menores. Este es el caso del secretario de la conferencia episcopal espanfola, Fernando Sebastión, quien ha llegado a afimar recientemente que los téologos de la liberación no son teologos de raza, pues no se ocupan de los grandes temas teologicos como la trinidad.

Tras las tomas de postura romanas contra la TL, algunos de estos sectores, otrora indiferentes, han adoptado una actitud beligerante. Se han aproximado a ella desde una lectura deformada y llena de prejuicios, para atacarla más de forma visceral que con argumentos de fondo.

Ven en la TL uma grave y mortifera amenaza contra la fe cristiana, ya que, a su juicio, esta se coloca al servicio de una política revolucionaria y de la ideologfa marxista. En esta línea hay que situar la "Instrucción sobre algunos aspectos de la teologia de la liberación," elaborada por la Sagrada Congregación para la Doctrina de la Fe," que acusa a la TL de recurrir a una hermenéutica dominada por el racionalismo; de haber tomado préstamos no demasiado críticos de la idología marxista, ruinosa para la fe (VI, 10); de hacer una lectura exclusivamente política de la Biblia; de entender la Iglesia popular latinoamericana como Iglesia de clase; de reducir la fe cristiana a un proyecto puramente terrestre, vaciándola de su dimensión transcendente.

Los sectores europeos - tanto teológicos como episcopales - que se mueven en el horizonte del documento romano han hecho causa común con los sectores latinoamericanos más combativamente antiliberacionistas, representados por el cardenal Lopez Trujillo, quien afirma que, a través de la TL, el marxismo se ha filtrado en el corazón mismo de la Iglesia y la lucha de clases ha venido a sustituir a la palabra de Dios. ${ }^{19}$ Postura reafumada hace apenas dos anos en la llamada Declaración de los Andes, donde se dice que, en ciertas teologias de la liberación, la praxis liberadora adquiere un sentido claramente tributario del marxismo y viene a constibuir un peligro fundamental para la fe del pueblo de Dios.20 En la reunión que dio lugar a esa declaración participaron, junto a obispos y teólogos latinoamericanos, teólogos europeos (también espaftoles).

En nuestro país esos seclores radicalmente contrarios a la TL están organizados en torno a la Universidad de Navarra y al Serninario de Toledo, bajo la tutela del cardenal primado Marcelo González. 
Tenemos que referimos también, aunque reconociendo una cierta distancia con los sectores citados, a los sucesivos pronunciamientos del secretario de la conferencia episcopal espanfola Fernando Sebastián, quien, si bien valora positivamente la actitud moral de los télogos latinoamericanos en favor de la liberación de los pobres, ha hecho descalificaciones más en la línea del cardenal Ratzinger que en la de otros obispos y teólogos europeos que, aun siendo críticos, mantienen una postura de diálogo y de apertura. Así se expresaba Sebastián en una "Carta abierta a Ignacio Ellacuría S.I.: "lo que muchos en la Iglesia pensamos es que la elaboración teórica de ese compromiso con los pobres que algunos teólogos latinoamericanos están haciendo no nos parece adecuda, sino que nos parece deficiente, equivocada y peligrosa"21

Una sospecha más matizada es la que aparece en la declaración de la Comisión Teológica Intemacional "Promoción humana y salvación cristiana" (afio 1977), que llama la atención sobre la ambiguledad que supone el empleo de las ciencias sociales en el trabajo teológico y muestra su temor ante la utilización del manxismo en la rellexión teológica.

Pero los sectores a los que estamos refiriéndonos, aun cuando ejercen una influencia no pequefia y nada desdeflable en el conjunto de la teología y de las iglesias europeas, no agotan las posturas de los teólogos europeos ante la TL.

\section{Apertura y diálogo}

Por ello, vamos a referimos, a continuación, a quienes mantienen una actitud diferente: más abierta, dialogal y permeable, como es la adoptada por la llamada teología progresista, que, reconoce, en líneas generales, la solidez leológica de la TL; valora positivamente, y asume en buena medida, las grandes intuiciones de la TL (la opción por los pobres, la centralidad de la praxis liberadora, etc.), hasta el punto de ejercer una influencia notable en el quehacer intelectual de no pocos teólogos; se muestra abierta a las interpelaciones que la TL lanza a las iglesias y teologlas del primer mundo; manifiesta una decidida voluntad de diálogo, donde se destacan tanto las contribuciones irrenunciables de la TL como sus límites.

De todos es conocido, como ya insinuamos anteriormente, el apoyo explícito que prestigiosos teólogos europeos han expresado a la TL y a sus cultivadores, sobre todo ante los ataques que vienen de Roma. Rahner salió en defensa de la ortodoxia de la TL en una carta que dirigió al cardenal arzobispo de Lima Mons. Landázuri, en la cual indicaba que "la voz de los pobres debe ser escuchada en la teología en el contexto de la Iglesia latinoamericana" y que "una teologla que debe estar al servicio de la evangelización concreta nunca puede prescindir del contexto cultural y social de la evangelización para que ésta sea eficaz, en la situación en la cual vive el destinatario." 22 Hacía ver igualmente al arzobispo de Lima la gran importancia de las ciencias sociales en la teología

En un testimonio de cálida solidaridad, el anciano télogo francés Chenu considera a Gustavo Gutiérrez como uno de los teólogos que más le han ilumi- 
nado y que mejor le han acompantado en su itinerario teológico, que le ha llevado a descubrir la praxis histórica como parte de la inteligencia de la fe..$^{23}$

Duquoc niega fundamento a las acusaciones de mesianismo temporal y marxistización que recaen sober la TL y precisa que esa teologia no viene a reeditar lo que fue la tentación permanente de la cristiandad: hacer del cristianismo una utopla política y el agente de una sociedad perfecta. ${ }^{24}$

Schillebeeckx reconoce que la TL es una teología joven y, por ello, puede mostrar "en algunos lugares enfermedades de infancia," pero a renglón seguido llama la atención sobre los enormes resultados cosechados en poco tiempo. Es más "se la estudia en todo el mundo, también en sus puntos débiles. ¿Qué teólogo no se equivoca alguna vez?"25

Alfaro la considera más que justificada y no cree que tenga que presentar credenciales ante otras teologías. De ella destaca la autenticidad de su compromiso con los pobres y su emerger del pueblo. Y mientas esto suceda, la teología de la liberación será una teología viva.26

Pero estos pronunciamientos no son simples declaraciones retóricas de apoyo moral o algo parecido. Detrás de ellas, y de otras similares que podrfamos citar, lo que se aprecia es la influencia notable que está ejerciendo en la orientación misma de la teología europea Vamos a verlo de manera más concreta en dos teólogos pertenecientes a dos confesiones cristianas: en el evangélico Molumann y en el católico Metz. Ambos son ejemplos paradigmáticos de la nueva sensibilidad europea hacia los problemas del tercer mundo y de la permeabilidad hacia la TL. En ambos se ha producido una evolución bien significaliva al respecto.

En una carta abierta al teólogo argentino Míguez Bonino en 1975, que tuvo un amplio eco en los medios teologicos europeos y latinoamericanos, Moltmann reaccionaba con dureza ante las críticas que la TL hacía a su teologia. Alli calificaba, sin matices, su utilización del marxismo. Hay en ella, afurmaba entonces, más de teorías sociológicas de socialistas occidentales que de la historia de la vida y del pueblo latinoamericano. ${ }^{27}$ Más que análisis detallados y precisos de la siuación del pueblo lo que Moltmann decía ver en las obras de esos teólogos eran "declamaciones del marxismo de seminario como cosmovisión." El proceso de liberación postulado para la América Latina por Gustavo Gutiérrez en su obra Teologla de la Liberación le parecía calcado de la historia europea de la libertad.

Diez afios después de aquella carta, Moltmann enjuicia la TL de modo muy distinto: reconoce sin sombra de duda su solidez teológica. Este es su testimonio. que me parece elocuente: "Los télogos de la liberación se han enraizado en las comunidades de base, que son un signo prometedor de reforma de la Iglesia y de la sociedad, y que inyectan vida de un modo que tiene algo de milagroso en una Iglesia, un poco apática de centralismo. Y ahí, ahora, la teología de la liberación tiene su relación organizativa ¡Distinta del marximo! Por esto puedo hoy decir que la teología de la liberación es una teología sólida y sana y dejo caer por 
completo las complejidades que yo fornulaba en aquella carta mía. Sé que existen muchas objeciones contra la teologia de la liberación, sobre todo a propósito de la Iglesia popular. Creo, sin embargo, que la experiencia que hay bajo el nombre de Iglesia popular es una nueva experiencia del Esplritu Santo, una nueva experiencia pentecostal. Es la comunidad de fieles que quiere ser sujeto de su propia historia ${ }^{28}$ Punto de vista coincidente con el de Metz, como después veremos.

La evolución del teólogo de la esperanza empieza a percibirse ya en El Dios crucificado, donde Sobrino aprecia una positiva influencia de la TL. En esa obra retoma las cuestiones de la "dialéctica negativa" y de la "teoría crítica" de Adomo y Horkheimer, junto con los puntos de vista de la antigua teología dialéctica y de la filosofia existencial, para elaborar, desde esos interlocutores, una theologia crucis, superadora tanto del teismo como del ateismo, redescubre la fuerza subversiva y liberadora de la cruz e inicia el nuevo camino por el cual van a transitar las teologfas históricas de la muerte de Cristo. "Sin percibir el dolor de lo negativo," sentencia Moltmann, "la esperanza cristiana no puede ser realista ni actuar liberadoramente. "29

Una mayor cercanía a la TL se observa en su obra La Iglesia fuerza del espiritu, donde capta perfectamente el carácter abierto y la pluridimensionalidad con que emplean los teólogos latinoamericanos el concepto de liberación: "desde la supresión de la explotación basada en el dominio de unas clases sobre otras, pasando por la eliminación política de la opresión y de la dictadura y la remoción del racismo, hasta la liberación de la esclavitud del pecado, experimentada en la fe, y la liberación escatológica del poder de la muerte." $30 \mathrm{La}$ opción por la liberación comporta, para Molunann, tomar partido por los humildes y oprimidos, al tiempo que supone la conquista de un futuro libre y humano para ellos. Aspectos ambos que cree están presentes en la TL. De ahı que, a su juicio, esa teologla puede superar la mentalidad particularista, que divide y domina a la humanidad, así como la mentalidad estrecha, fanática, que aparece en cada situación conflictiva ${ }^{\text {"31 }}$

Moltmann reconoce que la teología política europea y la TL latinoamericana, aun desarrollándose en contextos diferentes, tienen una misma lucha en común: "por la vida contra la muerte, por la liberación contra la opresión."

También en el pensamiento del téblogo catolico Johannes-Baptist Metz se ha producido una evolución notable a este respecto desde su primera orientación antropológica trascendental de los aflos sesenta, bajo la influencia de su maestro Rahner, pasando por la teología política, donde subraya el carácter público, crítico y práctico de la fe, hasta sus últimas obras, en las cuales disefia un paradigma de cristianismo profético, más allá de la religión burguesa, que devuelva el protagonismo a los sufrientes de la historia, a los perdedores, a las vfctimas del sisterna y haga justicia a los muertos.

Metz, asevera Ramos Regidor, es "el teologo católico europeo que mejor ha sabido expresar el desafío de las iglesias de los pobres a las iglesias de los paises 


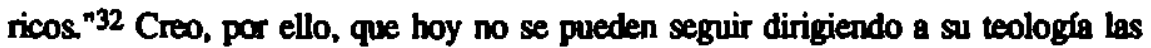
mismas críticas que en los primeros afios de la década de los setenta le hicieron de forma generalizada los teólogos latinoamericanos. Lejos de acorazarse ante las críticas de entonces, las ha asumido con una gran honestidad intelectual y ha caldo en la cuenta de que los cristianos de su pals han de vivir con la sospecha de ser opresores.

Metz ha llevado a cabo como ningin otro téblogo europeo, y en sintonia con la TL, una crítica a fondo de la razón modema y ha llamado la atención sobre los límites de los procesos de la ilustración; procesos que, a su juicio, amenazan a la teologia con una doble reducción: la reducción privatizante, que priva a la religión mesiánica de su consustancial dimensión crítico-pública; y la reducción racionalista, que lleva aparejada una renuncia radical a los mitos y símbolos por la sobrecarga cognoscitiva del abstracto mundo de las ciencias modemas. ${ }^{33}$ Uno de los cometidos centrales que le asigna a la teologia ante esta doble reducción es el de desenmascarar la idea de una sociedad totalmente secularizada y racionalizada como el auténtico mito generado por la absolutización no dialéctica de la ilustración.

Metz cree que las iglesias de los pobres, las comunidades de base y la TL latinoamericanas constituyen una poderosa ayuda para superar la doble reducción indicada, ya que en ellas se lleva a cabo una nueva relación entre gracia y liberación, entre experiencia de redención y experiencia de liberación; una nueva relación, "naturalmente no exenta de conflictos," entre religión y sociedad, entre mística y política; una nueva forma de aglutinar algo que a nosotros se nos presenta como compartimentado: teoria y praxis, lógica y mística, espiriu y resistencia, oración y política. ${ }^{34}$

Las comunidades de base y la TL comprometida con ellas dan un vuelco considerable a la manera tradicional de entender la autoridad en la teologí. La autoridad de que están investidas les viene de la autoridad sin voz de los que sufren, a través de los cuales se escucha la autoridad del Espritu, y de la santidad místico-política que viven. Esos teólogos pueden apelar a la autoridad de Jesús impotente a la sabiduría nacida del discipulado y al consenso de buen número de obispos encarnados entre los pobres.35 "La teologia," subraya Metz, "participa de esta autoridad en la medida en que participa en la praxis y la construcción de esta comunidad eclesial de base. ${ }^{36}$

Este nuevo modo de hacer teologia y la nueva idea de autoridad en el quehacer teológico comportan un cambio de lugar y posición, de sujeto y hasta de tema con respecto a la teología tradicional, y obliga, asimismo, a replantearse los sujetos, lugares, contextos e intereses de la teología.

Metz sigue considerando válida y necesaria la teologia académica profesional, que el representa. A ella le atribuye, entre otras, las siguientes funciones: integrar las nuevas experiencias en la Iglesia y la nueva praxis en la memoria total de la Iglesia, a fin de inpedir que se queden en algo pasajero y corran el peligro de Universidad Centroamericana "José Simeón Cañas" 
desintegrarse; confrontar esas experiencias con las reservas de fe de la Iglesia, ofreciéndoles el apoyo de la tradición; velar porque la 'base' eclesial no caiga en el aislamiento conceptual de una sectr.

Pero tanto las comunidades de base como la TL hacen tomar conciencia a la teología académica de su modestia y de la necesidad de autolimitación productiva. O dicho con otras palabras, la teología académica sigue siendo necesaria, pero no ya como la única forma de hacer teologfa, sino como un modo subsidiario. ${ }^{37}$

Metz considera necesario dar el paso de una Iglesia y una teologia culturalmente monocéntricas -que fueron las que estuvieron vigentes durante los siglos de predominio del helenismo y de la cultura europea - a una Iglesia y una teologia verdaderamente mundiales, universales, es decir, culturalmente policéntricas. ${ }^{38}$ De forma que desaparezca el predominio de la teologia europea sobre las teologras de los países pobres y se dé una inspiración mutua y una asimilación reciproca entre las diferentes teologias particulares.

Esta nueva optica da lugar a un giro copemicano en la comprensión de la Iglesia y lleva consigo la superación del imperialismo ejercido por las iglesias de Europa y Estados Unidos sobre las del tercer mundo: "La Iglesia católica ya no tiene simples sucursales en los parses fuera de Europa y América del Norte..., no 'tiene' simplemente una Iglesia del tercer mundo, sino que ésta, empíricamente hablando, 'es' una Iglesia del tercer mundo, cuyo origen historico es europeooccidental." 39

Metz aboga por un segunda reforma como requisito indispensable para que el cristianismo pueda seguir afirmando su propia identidad histórica en este paso de la sociedad burguesa al mundo posburgués. Pero no cree que dicha reforma venga ni de Wittenberg, ni de Roma, ni de la Europa cristiana de occidente, ni que sus protagonistas sean grandes reformadores, como en el pasado. Vendrá, más bien, del cristianismo liberador, tal como es vivido y formulado por las iglesias de los pobres, en las comunidades de base, las cuales, desde la base de la sociedad y de la Iglesia, se esfuerzan por combinar su praxis religiosa y su praxis social y acogen, en su comunidad eucarística, los conflictos. De esa manera, los cristianos dejan de ser objeto de asistencia social y eclesial y devienen sujetos de su historia religiosa y política ${ }^{40}$

El catolicismo de nuestros paises ricos tiene ante si la gran oportunidad histórica de aceptar esa misión reformadora de las iglesias pobres e integrarla en la Iglesia universal, de acoger ese nuevo modo de entender y vivir la libertad, y no bloquearla objetando que nos encontramos ante una manifestación particular de las iglesias del tercer mundo.

Si la TL hace de los pobres y de la opción preferencial por ellos el lugar teológico y epistemológico por excelencia, Metz se propone "mirar al escenario de la historia con los ojos de las víctimas" y ha renunciado a hacer teología de espaldas a los sufrimientos de los pobres y oprimidos del mundo. ${ }^{41}$ Las afinidades son manifiestas. 
En este clima de buena acogida y de interpelaciones muturas es donde hay que sibuar algunas de las lagunas de la TL sobre las que los teólogos europeos de talante progresista laman la atención y a las que muy brevemente vamos a referimos. 42

La TL justifica su discurso sobre el Dios de los pobres apelando a la praxis liberadora de los creyentes. A Dios se accede, afirma Gutiérrez, no por complicadas pruebas filosóficas o por razonamientos abstractos, sino "contemplíndolo y practicándolo." En la misma línea subraya Sobrino que "se va conociendo al Dios liberador en la praxis de liberación, al Dios bueno y misericardioso en la praxis de la bondad y de la misericordia, al Dios escondido y crucificado en el mantenerse en la persecución y en el martirio, al Dios plenificador de la utopla en la praxis de la esperanza"

Pero - y aqui viene la critica - se queda al nivel del lenguaje narrativo y apenas lega a rozar el debate abierto por la negación atea; no consigue hincar el diente a la crítica que del discurso sobre Dios hace la modernidad, cuando esa crítica también afecta a la TL. Es más, ni siguiqera se lo propone. Precisamente por no afrontar ese desafio en toda su densidad, el discurso latinoamericano liberador sobre Dios es calificado de fundamentalista Aquí se encuentra, quizá una de las causas, y no la menos importante, de las dificultades para entablar un diślogo entre la TL y la razón ilustrada y posilustrada.

Los teólogos europeos llaman también la atención sobre la pobreza epistemológica de la TL que, a su juicio, "permanece al nivel de la simple conciencia cristiana como mero portavoz que la amplifica, y raras veces alcanza un rango de reflexión estrictamente teologica "43

Esos mismos teólogos se refieren al empleo, por buena parte de los cultivadores de la TL, de una fundamentación bibilica ingenua y precrítica, que no parece tener en cuenta la exégesis cientifica.

Hay autores que radicalizan eca crítica y sitian a la TL del lado del discurso proclamatorio y testimonial; no la consideran propiamente teologia por entender que carece del mínimo crítico exigible a una teología rigurosa. 44

La TL da prioridad a la fuerza mesiánica del cristianismo y retoma las tradiciones y experiencias blblicas más subversivas y desestabilizadoras del orden establecido, como el éxodo, la predicación de los profetas, el mensaje y la praxis liberadoras de Jesús, etc. Hasta aquí nada que objetar. Antes al contrario, gracias a la TL recupera operatividad histórica una corriente biblica largos siglos secuestrada.

Ahora bien, la TL tiene "por adquirida la coincidencia entre el mesianismo y la afirmación de Dios", la unidad entre la praxis de liberación y el discurso de Dios. Sin embargo, esa coincidencia y esa unidad no sólo no son evidentes. sino que fueron cuestionadas por la modernidad y han sido negadas de forma explícita. Bloch, por ejemplo, considera el mesianismo como el núcleo central de la religión judeo-cristiana, que es necesario heredar, pero ello no implica, para él, Digitalizado por Biblioteca "P. Florentino Idoate, S.J."

Universidad Centroamericana "José Simeón Cañas" 
la afirmación de Dios, sino su negación. Dios es presentado por Bloch como "ideal utopicamente hipostasiado del hombre desconocido."45 El aleísmo constiurye, segín Bloch, el verdadero presupuesto de la utopía religiosa: "Sin atelsmo no hay lugar para el mesianismo." Un atelsmo que no se limita a ser simple negación, sino que es asunción de la herencia de la religión en su sustancia mesiánica.

A la vista de esa impugnación no vale afirmar sin más la coincidencia antes seftalada; hay que demostrarla ${ }^{45}$ En esa misma línea se pide a la TL que aclare una cuestión que permanece oscura: la relación de las promesas blblicas con el movimiento de nuestra historia, es decir, cómo traducir el mesianismo bíblico y su fuerza transgresora del orden existente en una praxis histórica de liberación, sin caer en ingenuos mesianismos políticos. Cuestion que es necesario abordar, a partir de la originalidad del mesianismo de Jesús, como hace, a mi juicio con gran acierto, Duquoc. 47

Los télogos europeos perciben también en la TL indelinición y ambigledad en lo que se refiere a las implicaciones sociales y políticas de esa teologia. Asf, por ejemplo, no aparece si la TL asume, aun con todos los correctivos necesarios para la America Latina, el sistema democrático como forma de convivencia en libertad o si se inclinan, más bien, por ciertas formas de populismo revolucionario, cuyo elemento fundamental es la movilización espontánea del pueblo, sin saber muy bien en qué puede terminar.

Otro punto sobre el que se pide clarificación es el que se refiere a la relación de la TL con los movimientos de liberación. Se tiene a veces la impresión de que actúa como sacralizadora de los mismos, sin tomar la debida distancia critica. Lo que no quiere decir que se le exija situarse al margen de ellos; antes al contrario, su inserción en los movimientos de liberación constituye una de sus originalidades y una de las claves de su identidad. Aunque debe huir de toda absolutización no dialéctica de los mismos.

Llama poderosamente la atención el que la violencia, realidad cotidiana y omnipresente en la vida del pueblo latinoamericano, apenes sea objeto de reflexión en la TL. Cuando se aborda el tema se hace sin entrar en él a fondo, siguiendo, en la mayorla de los casos, la doctrina social de la Iglesia al respecto. Y no es que se pida a los télogos de la liberación que entren en disquisiciones abstractas sobre el particular, pero si puede pedirseles que hagan un esfuerzo por entrar en esa materia con el mismo rigor y la misma profunidad con que abordan otras cuestiones fundamentales. El hecho de que sea un problema de especial complejidad no es razón para orillarlo.

Con frecuencia suelen hacerse identificaciones fáciles y caricaturescas entre el cristianismo liberador latinoamericano y la defensa de la violencia por parte de no pocos cristianos. Con frecuencia se presenta a los té́logos de la liberación como legitimadores de la violencia. Cosas ambas infundadas y falseadoras de la realidad. Con frecuencia se reduce el problema de América Latina al de la violencia y lo 
único que parece interesar a los de fuera es si el uso de la violencia está justificado o no. Con frecuencia al pedirles a los teólogos de la liberación que clarifiquen su posición en tomo a la violencia que vive el continente, se les está tendiendo la trampa saducea: si se muestran contrarios a ella, se les acusará de pecifistas ingenuos y conformistas; si la respuesta es afurmativa, se les acusará de dar la espalda al ideal evangélico.

Precisamente para evitar las simplificaciones que en torno al tema existen es necesario salvar la laguna que se observa en la TL.

\section{3. ¿Teologí europea de la liberación?}

Hemos de referimos, por fin, a aquellos teologos que se preguntan por las posibilidades y por la viabilidad de una teolog fa de la liberación en el primer mundo, y más en concreto en Europa. Esos teologos comienzan por reconocer la complejidad del problema; de ahí que hablen de la posibilidad, sin atreverse a dar una respuesta categórica.

No se les oculta que la teologia latinoamericana y la europea se situan en dos contextos bien diferentes, como tambien ha subrayado recientemente $\mathrm{C}$. Boff, quien se refiere a una triple diferencia: histórica, social y religiosa. Consideran inadecuada igualmente la transposición mimética de la TL latinoamericana a nuestro primer mundo. Pero, ¿se dan condiciones de posibilidad para elaborar una teologia europea de la liberación?

Para los teólogos de la liberación, la teologia es acto segundo, y ello en un doble sentido: en primer lugar, el discurso teologico viene despues de la experiencia de la fe vivida como praxis en el interior de los procesos históricos de liberación y como contemplación. En segundo lugar, la teologla no resulta lo más importante, es algo secundario, pues está al servicio de la evangelización de los pobres y de la liberación de los oprimidos. Estas son más importantes que la teologin $Y$ la liberación a la que se tiende "es en sI misma un proceso social, histórico, laico y autónomo, con su propia racionalidad. "48

Segín esto, una primera condición de posibilidad de una teologí de la liberación en el primer mundo sería la existencia de procesos de liberación, que impulsaran la transformación de las estructuras actuales y la existencia significativa y relevante de cristianos en dichos procesos. Obviamente esos procesos no tienen por qué ir a la zaga de los que se dan en América Latina.

Como bien ha subrayado Girardi, la TL parte de dos presupuestos fundamentales: uno metodológico, y es que la reflexión sobre el hecho religioso y cristiano debe realizarse a la luz de la dialéctica dominación-liberación; otro histórico que consiste en que, en este contexto. Jesús aparece como una alternativa a la sociedad de su tiempo.49

Segín esto, cabe preguntarse si existe en el "primer mundo" la dialéctica dominación-liberacion, si es tan central como para exigir una toma de partido y 
cuáles son sus principales manifestaciones. Lo que sf parece claro es que en el "primer mundo" las situaciones de opresión ofrecen una gran complejidad, de forma que no resulta fácil establecer una bipolarización tan definida como en el tercer mundo. Entre los factores que dificultan el establecimiento de esa bipolarización suelen citarse los siguientes. "La diversidad y fragmentación de los problemas, necesidades y conflictos; la dificultad en determinar un sujeto histórico calificable como 'los pobres;' la creciente importancia que en la sociedad modema adquieren las clases medias y la dificultad de encuadrarlas en el conflicto opresores-oprimidos; la fuerte diversificación de las clases populares, particularmente la clase obrera, que no permite encuadrarlas en un proyecto histórico común; la ausencia de un proyecto revolucionario digno de credibilidad en los mismos partidos de la izquierda que priva de contenido polĺtico concreto la opción por los pobres." 50

Pues bien, teniendo en cuenta las cuestiones aqui apuntadas, hay télogos europeos de talante progresista que creen necesaria en Europa la elaboración de una "teologia política profética"s1 con unos rasgos peculiares: "que tome plenamente en serio el desaffo de la teologia de la liberación y reflexione sobre Dios y el 'primer mundo' bajo el signo de la opción preferencial por los pobres; ${ }^{n 52}$ que no renuncie a la historia de la libertad y a la ilustración, pero siendo consciente, a su vez, de la dialéctica de la ilustración; es decir, que sepa responder lúcida y críticamente a los desafíos provenientes de la razón ilustrada y posilustrada, asumiendo sus conquistas irrenunciables y descubriendo sus límites y reduccionismos; ${ }^{53}$ que dé centralidad a la praxis liberadora y se libere de la abstracción en que frecuentemente cae atrapada la teología europea.

\section{Conclusion}

Espero haber conseguido con este trabajo el objetivo que me propuse al comienzo: dar cuenta, grosso modo, de la recepción que los télogos europeos, y especialmente los llamados progresistas, han hecho de la TL. Para ello he intentado exponer los diferentes puntos de vista con la mayor objetividad posible, sin dejarme llevar por el apasionamiento. Aunque no creo haber ocultado mi sintonía con la TL. Cosas ambas que no tienen por qué estar reflidas. Me siento, además, muy cerca de teólogos europeos como Molumann y Metz, y comparto la propuesta, hecha por Greinacher, de una teologia profética en el "primer mundo".

TL y teologia europea progresista no son hoy compartimentos estancos; entre ambas hay más afinidades que las que incluso una y otra alcanzan a ver. Los quince aflos de diálogo ininterrumpido han permitido quebrar las rigideces y los recelos iniciales, sin , por ello, hacer tabla rasa de las diferencias.

Quiero terminar esta exposición con unas palabras de Girardi, uno de los teólogos europeos que con más rigor intelectual vienen planteándose, desde hace anos, la posibilidad de una teología europea de la liberación: "Por difícil que resulte en Europa una teología de la liberación realizada en la perspectiva de una 
cultura altemativa, la fe cristiana, con su original fuerza subversiva, sigue siendo, también en Europa, un fermento de creatividad cultural. Si no existe una total autonomía de la fe, si existe una autonomía relativa de la misma que le permite inspirar iniciativas historicas." ${ }^{\mathrm{N} 4}$

\section{NOTAS}

1. J. L Segundo, De la sociedad a la teología. Buenos Aires: Cerlos Lohle, 1970, 11-12

2 H. Assmann, Opresion-liberación. Desafto a los cristianas. Montevideo: Tierm Nhéven $1971,51$.

3. J. B. Metz, "Le teologir en el ocaso de in Modemidad" Conciliton, 1984, 191, 34.

4. C. Boff, "Carta de un télogo latinosmeriono a un cristiano europeo." El 'Ciervo" (mayo 1985), 31-36.

5. Citado en D. Yallop, En nombre de Dios, Barcelons: Planeta, 1985, 6.

6. Consejo de redacción, "Afumaciones pars un tiempo de crisis." Iglesio vive, 1984, 72.

7. Cl. Geffre, "La commoción de una teologin profética." Coneiliun, 1984, 96, 303.

8. J. Sobrino, "El conocimiento teológico en la teología europen y latinomericane," en Varios, Liberacion y cautiverio, Mexico, 1976, 177-207; id., "Teologin de ln liberación y teologia europen progresista." Misión Abierta, 1984, 11-26.

9. G. Gutierrez, La fuerza historica de las pobres. Salamanca: Sigueme, 1982, espec. 213290; id., Lo verdad los hard libres. Lima: CEP, 1986.

10. G. Gutierrez, La verdad las hare libres, op. eit., 38.

11. Ibid.

12. J. L Segundo, "Cepielismo-socialismo, 'crux theologica'." Concilium, 1974, 96, 401422.

13. J. Sobrino, "Teologle de ln liberación y teologin europes progresism" Mision Abiena, $1984,4,16$

14. Ibid.

15. L. Boff, Teologle de la liberación y del couriverio. Mndrid: Paulinas, 1978, 94

16. E Dussel, "Daninación-liberneión. Un discurso veológico distinto" Conciliven, 1974, 96, 328-352.

17. R. Alve, Cristianions, ¿opio o liberacion? Salamenca; SIgueme, 1973, 95-114.

18. E. Dussel, "Teologias de ln 'periferia' y del 'centro' ¿Encuentro o confrontación?" Concilium, 1984, 191, 141-154, esta cith ee encuentra en la p. 154.

19. Cf. Adista, 11-12-13 de cotubre de 1982.

20. Cf. el informe publicado por Vida Nueva sobre ese encuentro, n. 1498, 35.

21. Diario YA, 22 de diciembre de 1985.

22. Misión Abierla, 1984, 4113.

23. M-D. Chenu, La auforidad del evangelio y la seologha, en Varios, Vida y reflexión. Aportes de $b$ teología de la liberación al pensamiento teologico actual. Limn: CEP, 1983, 19.

24. Ch. Duquoc, "Mesianiomo y teologe de la liberacion," en Varios, Vida y refierión, op. eif. 101-120. Bre trabajo ha sido recogido posteriormente en la reciente obse de Duquoc, Mesianismo de Jesús y discreción de Dias. Madrid: Cristiondad, 1986.

25. E. Schillebeecko, "Una opcion equivoceds" Misión Abiera", 1985, 1, 102

26. J. Alfaro, en Varios, Liberación y cautiverio, op. cit. 582

27. J. Molimann, "La teologla de la libención. Carn abiern a Jose Miguez Bonino" Iglesia Viva, 1975, 60, 559-570. 
28. J. Molonenn, "Dalla teologle politica all' etica politio" Ed Regno, 1984, 507, 205.

29. J. Molumann, El Dias erucificado, Salmmanca; Sigueme, 1975, 15.

30. J. Molmann, La Iglesia fuerza del espirifu, Salemanca: SIgueme, 1978, 34-35.

31. Ibid.

32. J. Ramos Regidor, "Europa y las cologins de la liberación," Iglesio Viva, 1985, 116117, 177. Este trabajo de Ramos Regidor, al como su obre Gesu e il risveglio degli opressi, Milm: Mondadori, 1981, me han sido de gran utilidad para el estudio sobse las relaciones entre is TL y la teologin europea. .

33. J. B. Metz, "Ln teologin en el ocaso de lin modernidad," artialo citado, 33.

34. Ibid., 38-39

35. J. B. Mez, "Un nuevo modo de hacer teologin Tres tesis," en Varios, Vida y refierión, op. eir., 54; of. en exts misma línes el n. 200 de Concilien (1985), dedicado a "E magirserio de los fieles" y expecinlmente E. Schillebeedox, "La autoridad doctrinal de lot fieles. Reflexión a partir de la estructur del Nuevo Testamento," 21-32; J. Sobrino, "Le 'uroridad doctrinal' del pueblo de Diou en Amtrica Latinn, 71-82

36. J. B. Metz, "Un noevo modo de hecer teologie Tres tesis, en Varios, Vida y refiexión, op. cir., 53.

37. Ibid., 55-56.

38. J. B. Metr, "La teologin en el casso de ln modemidad," artralo cindo, 37.

39. J. B. Metz, "Ante un mundo en cerobio." Concilium, 1983, 190, 510.

40. J. B. Met, Al di Ld della religione borghese. Brocis: Querinitma, 1981, 62-82

41. J. B. Metz, "Toologin cristima después de Auschwizz" Concilium, 1984, 195, 209-222.

42. C,, J. J. SGnchez, "Teologla polltice y teologle de la liberacín. Un discuno crítico liberndor sobre Dios," en Varion, El Dias de la reologí de la liberación. Salamanca: Secreturiado Triniturio, 1986, 118-120.

43. A. Fierro, $E$ l evangelio beligerante, Eatella: Verbo Divino, 1975, 382

44. A Fierro califica la primera obre de G. Gutikrez Teologí de la liberación de excelente libro estimanial y de profesión de fe de un cristinnimo polítictunente compromerido, y la catsloge entre ln teologin retorica, $E l$ ewangelio beligerante, op. cit., 277-78. Parecida valoración hace de la TL en Presentación de la teologia, Barcelens: Liia, 1980.

45. E Bloch, El principio esperanza, Vol. III. Madrid: Aguilar, 1980; of. el capirulo 7 de mi libro Cristianismo: profech y utopla. Estella: Verto Divino, 1987, que lleve por úfulo "Ulopin y espernza en el cristimimo segín Emst Bloch."

46. Cf. Ch Duquoc, "El Dios de Jesul y la crisis de Dios a nuestro tiempo, en Varios, Jesueristo en la historia y en la fe. Salunance; Slgueme, 1977, 50. En exie excelente trabajo de Duquoc aborda el deanfí blochinno y ofrece algunas vin de requesta.

47. Ch. Duquoc, Mesianismo de Jesús y diserecion de Dios. Madrid: Cristiandad, 1986, 137138.

48. J. Remos Regidor, "Europa y lat veologins de In libencion." Iglesia Viva, 1985, 1161I7, 185.

49. G. Girardi, "Posibilided de unn teologin exupea de ln libereción" Misión Abierke, 1984, 4. 157. Cf. del mismo autor otros dos estudios de gran consistencin teológica y culoural: Pasibilied di wa teologia europea della liberatione. "Idoc intemationale," 1 (1983) 30 47; "De la 'Tglesin en el mundo' a la 'Tglesin de los pobres.' E Valicano II y la teologia de ln liberación," en C Floristin y J. J. Tamnyo, EI Vaticano II, veinte afias despuls, Madrid: Cristiandad, 1985, 429-463.

50. G. Giradi, "Posibilidad de une teologin europea de la liberación," artíalo citado 153.

51. La propuesu del ceólogo alerán N. Greinacher, "¿Teologin de la liberación en el primer mundo"7" Concilium 1986, 207, 253-264. En este articulo, que me perece progrnmírico, al autor esboza algunos de los elementos que al consider importintes a la hor de elabornt une teologie proftica en el primer mundo. Ast, por ejemplo, luchar contre wa forme de neocolonialimo político y cultural; cuestianer de rafz el modelo conoumista, que viene a destruir la cultur del individuo, combalir la alienación por la 
riqueza, que en erpectica del primer mundo; un nuevo estilo de vida en los ámbitos del individwo, de la familie, de le Iglesin y de la socieded; aftica del sistems econónioo capinalists; opción por los pobre, tunto los del tercer mundo cono los que genera el siatema capiulinta en el priner mundo; asumir la teorla de la dependencie, reconociendo que umbien nosotros comos opresores; erfiea de la ayuda al desarrollo; critica del pecado estructurl que supone el sirtema ecońmico mundial.

52. N. Geinacher, artíalo citado, 255.

53. Cf J. I Gonzflez Faus, "Los pobres luger teologico," en Varios El secuestro de la verdad, Santander: Sal Terrae, 1986, 103-159, sobre todo el aparado III, 2: "El pobre como critia teologica a In Dusnción (pp. 143-156). "Los pobres dejan al descubierto," mever con egudeza Gonzflez Faus, "tres grandes fallos de la Ilustración, los tres presentados como ideales té́ricos en el siglo XVIII por el movimiento ilustrado. Ellos con: un progreso que es, en buens medidn, contrario a le igualded; uns nzón que no tiene suficientemente en cuenta la fratemidad; el pecado contrio a la liberud Frente enes carencias de ln Dustración, los pobres aportan tres categorins a la leologin par eu dílogo con el mundo: un progreso solidario, une mzon dielogal y una referencie a las victimas del sisterms impenante.

54. G. Ginadi, "Posibilided de une teologin europes de le liberación," arficulo citado, 159. 